\title{
Research and Implementation of the Strategy of Employment in Engineering based on Extension
}

\author{
Zhang Xihua \\ Baicheng of Jilin province, China \\ email :103718606@qq.com
}

Keywords: extension model; extenics; Strategy

Abstract. The author of this paper uses extenics and solves the problem of the profession about the employment problem of software engineering in the contradiction of employment and creates a better employment strategy and intelligent software, finally provides a certain significance for solving the employment problem.

\section{Introduction}

At present, the prospect of high quality graduates in computer software engineering is very promising. But how to cultivate high-quality software engineering talent has become the university software engineering which must consider the problem. At present there are many graduates of software engineering in China every year. But the shortage of advanced software talents has become a bottleneck restricting the rapid development of China's software industry.

How to solve the above problems of supply and demand has become the basic problem of students' employment urgently. Extenics is the study of the possibility of the development of things and the rules and methods of innovation, and the science of solving contradictory problems. As a result, the computer and the strategy to solve the problem of contradiction system extenics can establish a clear software engineering professional training mode of information and knowledge. So as to produce the training pattern and employment strategy which forms the intelligent software, it is of great research significance.

\section{The Definition of Contradiction between Supply and Demand and the Establishment of Extension Model}

Take the software engineering major of a university as an example, the number of graduates is 160 , the employment number is 120 , the high quality software works 96 people, the social demand rate reaches $100 \%$. The model is established as follows:

$$
\begin{aligned}
& \boldsymbol{P}=\boldsymbol{g} * \boldsymbol{l}=[\text { Social need, number, 160]* } \\
& \text { ([ } \left.\begin{array}{ccc}
\text { Software engineering, } & \text { the number of jobs, } & 120 \\
\text { the number of graduation, } & 160
\end{array}\right] \wedge
\end{aligned}
$$

In extenics, the correlation function is used to describe the degree to which elements of the domain are characterized by a certain nature. According to the regular $X=\langle a, b\rangle, M \in X$, a finite interval is [1]:

$$
K(x)=\left\{\begin{array}{l}
\frac{x-a}{M-a}, x \leq M \\
\frac{b-x}{b-M}, x \geq M
\end{array}\right.
$$

Calculated: $\quad k_{1}\left(\frac{120}{160}\right)=\frac{0.75-0.9}{1-0.9}=-1.5 \quad, \quad k_{2}\left(\frac{96}{160}\right)=\frac{0.6-0.9}{1-0.9}=-3 \quad(a=0.9, b=1.5, M=1)$ 
$K(l)=k_{1}(l) \wedge k_{2}(l)=\min \left\{k_{1}, k_{2}\right\}=-3<0$. So the problem is the incompatibility problem.

\section{Expansion and Extension transform of the Problem}

In extenics, the expansion and inference of the base element can be used to expand the rules of reasoning. By expanding the rules of reasoning, the problem of divergence, correlation, implication and expansion can be obtained.

Use of divergence rule: $l_{0}-\mid\left\{l_{1}, l_{2}, \ldots l_{n}\right\}$, expand and analyze the above issues:

$$
\begin{gathered}
l_{1}=\left[\begin{array}{ccc}
\text { college, } & \text { develop, } & \text { training programs } \\
& \text { improve, } & \text { student skills }
\end{array}\right] \\
l_{2}=\left[\begin{array}{ccc}
\text { students, } & \text { attend, } & \text { training } \\
& \text { improve, } & \text { comprehensive level }
\end{array}\right]
\end{gathered}
$$

And then the extension transformation is

$$
\begin{gathered}
T_{l} l=l_{1}=[\text { Software engineering, the number of jobs, } 150] \\
T_{l} l=l_{2}=[\text { Software engineering, Senior talent number, } 146]
\end{gathered}
$$

The formula 1 is calculated:

$$
\left\{\begin{array}{l}
k_{1}\left(\frac{150}{160}\right)=\frac{0.9375-0.9}{1-0.9}=0.375 \\
k_{2}\left(\frac{146}{160}\right)=\frac{0.9125-0.9}{1-0.9}=0.125
\end{array}\right.
$$

After the extension transformation, $K(l)=k_{1}(l) \wedge k_{2}(l)=\min \left\{k_{1}, k_{2}\right\}=0.125>0$, after the conditional transformation, the problem becomes a compatible problem.

\section{Solution of Incompatible Problems - the Formation of Extension Strategy}

Based on the optimization of extension, the author chooses the optimal strategy of extension and selects one or several strategies which are higher, which can be used as a reference strategy in decision making. According to the above, $l_{0}-\mid\left\{l_{1}, l_{2}, \ldots l_{n}\right\}$ after the divergence [2], here are two strategies:

1. Facing the transformation of colleges, enterprises are introduced into classroom, students' working ability has increased by $60 \%$ compared with the past average, and students need to spend 8000 yuan per person.

2. Senior students in university are sent to corporate training, and trained for six months, and then recommend the employment, the ability is increased by $80 \%$. They do not need to pay fees during the training, but must be more than 2 years of contract with enterprises.

Following two strategies are evaluated. The specific steps are as follows [3][4][5]. (1) According to expert opinion, decision makers' opinions and the actual situation, identifying characteristics of evaluation $C_{1}, C_{2}, C_{3}$. And its values $V_{1}, V_{2}, V_{3}$ :

$$
\begin{gathered}
\left(C_{1}, V_{1}\right)=(\text { ability, improve the degree of }) \\
\left(C_{2}, V_{2}\right)=(\text { Students spend, amount }) \\
\left(C_{3}, V_{3}\right)=(\text { Sign a contract, time })
\end{gathered}
$$

(2) According to the importance of evaluation characteristics, assign weights to each other among[0,1]. Set of weights $\alpha_{1}=0.4, \alpha_{2}=0.3, \alpha_{3}=0.3$.

(3) Establish different correlation functions and compute the value of the associated function. 


$$
\begin{gathered}
k_{1}(x)=\left\{\begin{array}{cc}
1 & \text { Improve the degree of } \geq 75 \% \\
0.5 & \text { Improve the degree of } \geq 60 \% \\
0.3 & \text { Improve the degree of }<60 \%
\end{array}\right. \\
k_{2}(x)=\frac{15000-x}{15000} \text { (formula1) } \\
k_{3}(x)=\frac{3-x}{3} \text { (formula1) }
\end{gathered}
$$

Use the above correlation function, the value of the associated function:

$$
\begin{gathered}
K_{1}\left(k_{1}\left(A_{1}\right), k_{1}\left(A_{2}\right)\right)=(0.5,1) \\
K_{2}\left(k_{2}\left(A_{1}\right), k_{2}\left(A_{2}\right)\right)=(0.467,1) \\
K_{3}\left(k_{3}\left(A_{1}\right), k_{3}\left(A_{2}\right)\right)=(1,0.333)
\end{gathered}
$$

(4) The standard correlation degree of each evaluation feature of computer strategy.[5][6][7]

Canonical correlation

$$
K_{i}^{*}\left(A_{i}\right)=\left[\begin{array}{l}
k_{1}\left(A_{i}\right) \\
k_{2}\left(A_{i}\right) \\
k_{3}\left(A_{i}\right)
\end{array}\right]
$$

So

$$
\begin{gathered}
K_{1}^{*}\left(A_{1}\right)=\left[\begin{array}{l}
k_{1}\left(A_{1}\right) \\
k_{2}\left(A_{1}\right) \\
k_{3}\left(A_{1}\right)
\end{array}\right]=\left[\begin{array}{c}
0.5 \\
0.467 \\
1
\end{array}\right] \\
K_{2}^{*}\left(A_{2}\right)=\left[\begin{array}{l}
k_{1}\left(A_{2}\right) \\
k_{2}\left(A_{2}\right) \\
k_{3}\left(A_{2}\right)
\end{array}\right]=\left[\begin{array}{c}
1 \\
1 \\
0.333
\end{array}\right]
\end{gathered}
$$

(5) According to different requirements of different problems, the comprehensive optimal calculation method is selected to calculate the comprehensive optimization of each strategy.

$$
C\left(A_{i}\right)=\sum_{i=1}^{2} \alpha_{i} K_{i}^{*}\left(A_{i}\right)
$$

Comprehensive optimization

$$
\begin{gathered}
C\left(A_{1}\right)=\left[\begin{array}{lll}
0.4 & 0.3 & 0.3
\end{array}\right]\left[\begin{array}{c}
0.5 \\
0.467 \\
1
\end{array}\right]=0.69 \\
C\left(A_{2}\right)=\left[\begin{array}{lll}
0.4 & 0.3 & 0.3
\end{array}\right]\left[\begin{array}{c}
1 \\
1 \\
0.333
\end{array}\right]=1.699
\end{gathered}
$$

(6) According to the ranking of the strategy, select the superior as the reference strategy for the decision maker. According to the above calculation $C\left(A_{2}\right)>C\left(A_{1}\right)$, so $A_{2}$ is the better.

\section{Conclusion}

According to the problem of supply and demand contradiction faced by software engineering professional employment, the specific solution is given. In different specialties, the evaluation model of multi-index parameters is established by using the extension evaluation method, and the evaluation results are expressed quantitatively, which can provide an excellent strategy for colleges and universities. 


\section{References}

[1]Yang Chunyan, Cai Wen. Extension engineering (J). BeiJing: Science Publishing, 2007. 1-206

[2]Cai Wen. Extension sets and incompatible problems (J). Journal of Scientific Exploration, 1983, 1: 83-97

[3]Yang Chunyan, Li Weihua, Li Xiaomei. Research progress on the theory and method of intelligent processing of contradictions (J). Journal of Guangdong University of Technology, 2015, 28: 86-93

[4 ]Cai Wen, Yang Chunyan, Linwei Chu. Extension engineering method (M). Beijing: Science Publishing, 2016:1-17

[5]Yang Chunyan, Cai Wen. Extension information-knowledge-intelligent formal system research (J). Journal of intelligent systems, 2007, 2:9-11

[6] Cai Wen. Introduction to extension. System engineering theory and practice (J), 1998, 18:76-84

[7] Yang Chunyan, Cai Wen. The research progress of correlative functions of extension (J). Journal of Guangdong University of Technology, 2015, 29:7-14 